\title{
DERECHOS DEL EMPLEADOR A LA ORGANIZACIÓN Y DIRECCIÓN DE LA EMPRESA, Y LÍMITES
}

\author{
Dra. Cristina Mangarelli* \\ Universidad de la República, Uruguay
}

\begin{abstract}
RESUMEN: A partir de los elementos definitorios del contrato de trabajo, la autora presenta los que debieran ser los límites al poder de dirección y organización del empleador. Se analizan los diversos alcances de tales poderes empresariales, bajo un método de ejemplificaciones no taxativas de lo que pueden considerarse legítimos alcances de estas facultades. Ya desde una perspectiva meramente dogmática se entra al ámbito de los límites, los que vienen dados por ciertos principios generales, tales como, buena fe, justificación, proporcionalidad y no discriminación. Finalmente se plantean criterios para determinar la ilicitud en el ejercicio de los poderes empresariales y cómo se modalizan con el ejercicio de la huelga.
\end{abstract}

Palabras clave: poder empresarial, facultad de dirección, límites, derechos fundamentales

ABSTRACT: From the defining elements of the employment contract, the author presents wich should be the limits to the the employer's powers of direction and organization. The various scopes of such corporate powers are analyzed under a non-exhaustive method of instantiations of what can be considered legitimate scopes of these powers. Then, from a purely dogmatic perspective the author enters into the the field of the limits, which are given by certain general principles, such as good faith, justification, proportionality and non-discrimination. Finally, the criteria to determine the illegality in the exercise of corporate powers and how are modalize with strike action are presented.

Key words: corporate powers, direction faculty, limits, fundamental rights

\section{DERECHOS DEL EMPLEADOR A LA ORGANIZACIÓN Y DIRECCIÓN DE LA EMPRESA}

\subsection{Concepto. Fundamento}

El derecho de dirección del empleador no puede explicarse sin abordar previamente la noción de contrato de trabajo. Por el contrato de trabajo el trabajador se obliga a prestar un trabajo personal en favor de otra persona y bajo sus órdenes, a cambio de una remuneración. El contrato de trabajo entonces reconoce ${ }^{1}$ el derecho del empleador a dirigir el trabajo.

El derecho del empleador de dirección surge de "la naturaleza" del contrato de trabajo², por lo que rige aun sin norma expresa que lo establezca. El contrato de trabajo es pues el fundamento de este derecho de dirección ${ }^{3}$. Sin perjuicio de considerar que tanto el derecho de dirección como

\footnotetext{
* Profesora de Derecho del Trabajo y de la Seguridad Social, Facultad de Derecho de la Universidad de la República, Uruguay.

Seńalan Alonso Olea y Emilia Casas BaAmonde que el contrato de trabajo "atribuye" un poder directivo al empresario sobre el modo de la prestación. Véase Derecho del Trabajo. 10 ed. Madrid, España: Universidad Complutense de Madrid, 1988, p. 315.

2 Hueck Alfred y Nipperdey H. C sostienen que el poder directivo "resulta de la naturaleza misma de la relación de trabajo dependiente". Véase Compendio de derecho del Trabajo. Madrid, España: Editorial Revista de Derecho Privado, 1963, p.99.

3 Olea Alonso; Emilia Casas Baamonde Emilia, op. cit. (n. 1), pp. 315-316. Señalan que la fuente de este poder está en el contrato. Palomeque López Manuel Carlos; Álvarez de la Rosa, Manuel sostienen que "el fundamento" del poder para organizar y ordenar las prestaciones es el contrato de trabajo. Véase Derecho del Trabajo. 17º ed. Madrid, España: Editorial Universitaria Ramón Areces, 2009, p. 534.
} 
Cristina Mangarelli / Derechos del empleador a la organización y dirección de la empresa, y límites

el de organización de la empresa derivan de la libertad de empresa (derecho fundamental) y de ahí que puedan ser considerados derechos fundamentales.

Se ha explicado el derecho de dirección del empleador a partir de la noción de dependencia jurídica ${ }^{4}$. Sin embargo, si se constata la existencia de dependencia jurídica es porque se dirigió el trabajo ${ }^{5}$. Por ello entiendo que el derecho del empleador de dirección no deriva de la subordinación del trabajador sino de un contrato o relación en el que aparecen dos rasgos distintivos: la dirección y la subordinación. Con ello apunto a señalar que no puede perderse de vista la importancia del derecho de dirección para diferenciar el contrato de trabajo de otras relaciones jurídicas ${ }^{6}$.

No siempre se hace referencia al "derecho" del empleador de dirección, sino que es más común la expresión "poder" o facultad de dirección. De todos modos algunos autores lo analizan como "derecho" del empleador de dirección y organización de la empresa7.

En cuanto al concepto, el "derecho de dirección" de la empresa significa que de acuerdo con el contrato de trabajo el empleador tiene derecho a dirigir el trabajo, esto es a dar órdenes acerca del trabajo contratado sobre el modo, tiempo y lugar de la prestación ${ }^{8}$.

Y el "derecho de organización" de la empresa implica la facultad de organizarla en cuanto a los aspectos económicos y técnicos.

Por lo general en las constituciones se encuentra reconocida la libertad de empresa como derecho fundamental, y también el derecho de propiedad ${ }^{9}$. En la Constitución de Uruguay la libertad de industria y comercio se encuentra reconocida en el artículo 36 y el derecho de propiedad en los artículos 7 y 32. La Carta admite limitaciones en función del interés general por ley.

En la Declaración Sociolaboral del MERCOSUR en el Capítulo de Derechos Individuales y luego de hacer referencia a los derechos individuales del trabajador aparece bajo el título "Derechos de los empleadores" (artículo 7) el "derecho" del empleador "a organizar y dirigir económica y técnicamente la empresa, de conformidad con las legislaciones y las prácticas nacionales".

Algunos Códigos de Trabajo o leyes especiales reconocen en forma expresa este derecho del empleador de dirección de la empresa, aunque con límites que son indicados en la propia normativa.

\footnotetext{
En ese sentido puede verse Hueck y Nipperdey, op. cit. (n. 2), p. 98. Estos autores entienden que el deber de obediencia del trabajador es característico de la relación de trabajo y dicho deber "justifica el derecho del empleador a la dirección del trabajo". Квотоsсніn seńala que el derecho de dirección del empleador "es el corolario de la dependencia personal en la que el trabajador se ha colocado". Véase Tratado práctico de derecho del trabajo. Vol. I. 3a ed. Buenos Aires, Argentina: Ediciones Depalma, 1978 , p. 196.

Si se trabajó bajo órdenes, éstas se impartieron previamente.

6 En una línea similar Supiot señala que “...el poder de dirección que se ejerce sobre el trabajador constituye el criterio por excelencia para definir el contrato de trabajo, lo que permite distinguir al trabajador de cualquier otra forma de actividad económica que se ejerce a título oneroso para otro". Y en otro pasaje expresa que la caracterización del contrato de trabajo se encuentra en la pareja autoridad/subordinación. Véase Crítica del derecho del trabajo. Madrid, España: Ministerio de Trabajo y Asuntos Sociales, 1994 pp. 138 y 137, respectivamente.

Квотоschin hace referencia al "derecho de dirección del empleador", op. cit. (n. 4), p. 196; Hueck y Nipperdey lo denominan "poder de dirección del empleador", op. cit. (n. 2), pp. 98 y 113; Alonso Olea y Emilia Casas BaAmonde analizan "el poder de dirección” del empresario, op. cit. (n. 1), pp.315-320; PAlomeque López y Álvarez de la Rosa estudian "el poder de dirección del empresario", op. cit. (n. 3), p. 534; Pélissier, Jean; Supiot, Alain; Jeammaud, Antoine, refieren al "poder de dirección” del empleador. Véase Droit du travail. 23e Edition. París, Francia: Dalloz, 2006, pp. 990-991, 1276.

8 En este sentido Alonso Olea y Emilia Casas Baamonde, op. cit. (n. 1), p. 316; Hueck y Nipperdey, op. cit. (n. 2), p. 98.

9 La Constitución de la República Dominicana (2010) reconoce la libertad de empresa, comercio e industria (artículo 50) y el derecho de propiedad (artículo 51) en el capítulo de derechos fundamentales. El derecho a la propiedad está reconocido en la Declaración Universal de Derechos Humanos (artículo 17) y en la Declaración Americana de los Derechos y Deberes del Hombre (artículo XXIII). Los derechos del hombre se encuentran limitados por los derechos de los demás (Declaración Americana de los Derechos y Deberes del Hombre artículo XXVIII).
} 
En el Estatuto de los Trabajadores español, en el artículo 20 num. 1 se indica: "El trabajador estará obligado a realizar el trabajo convenido bajo 'la dirección ' del empresario o persona en quien éste delegue"; en el artículo 5 lit. c) se prevé como uno de los deberes básicos del trabajador: "Cumplir las órdenes e instrucciones del empresario 'en el ejercicio regular de sus facultades directivas '”; y en el artículo 1 se expresa que será aplicable dicho Estatuto a los trabajadores que voluntariamente presten servicios retribuidos por cuenta ajena "y dentro del ámbito de 'organización y dirección` de otra persona, física o jurídica, denominada empleador o empresario" (los resaltados son agregados).

En la Ley de Contrato de Trabajo argentina, se reconoce al empleador "la facultad de organización" de la empresa y la "facultad de dirección" (artículos 64 y 65).

Este derecho de dirección debe ejercerse atendiendo a los fines de la empresa y a las exigencias de la producción, "sin perjuicio de la preservación y mejora de los derechos personales y patrimoniales del trabajador", como lo señala la LCT argentina en su artículo 65. En una línea similar, el Estatuto de los Trabajadores español hace referencia al "ejercicio regular" de la facultad de dirección en los artículos 5 lit. c) y 20 num 2.

En Uruguay, la norma no reconoce al empleador estas facultades de organización y dirección, sin perjuicio de lo cual teniendo en cuenta que surgen de la naturaleza del contrato de trabajo no se ha discutido su vigencia ${ }^{10}$.

En la actualidad, este derecho de dirección no siempre lo ejerce el "empleador". En el caso de trabajadores de empresas suministradoras de mano de obra, los trabajadores se encuentran en la planilla de trabajo de estas empresas y sin embargo reciben las órdenes de la empresa cliente en la que prestan servicios.

\subsection{Alcance}

Señalaré a continuación algunas consideraciones generales acerca del alcance del derecho de dirección del empleador.

\subsection{1 Órdenes o instrucciones impartidas directamente por el empleador o por delegación}

Las órdenes o instrucciones las imparte el empleador directamente o por delegación (jefes, capataces, supervisores, etc.).

Estos representantes hacen responsable al empleador por los actos realizados en el ejercicio del poder de dirección. En algunos casos, el empleador será responsable por culpa en la elección o en la vigilancia de dichos supervisores. Ello sucede por ejemplo, en situaciones de acoso laboral. Los estudios sobre el fenómeno de la violencia en el trabajo e incluso las leyes aprobadas en varios países determinan que el empleador deba prestar especial atención en la elección, formación y control de actuación de los supervisores con relación a este tema.

\subsection{2 Órdenes o instrucciones individuales y generales}

Las órdenes o instrucciones podrán ser individuales y también generales. En los reglamentos internos se suelen encontrar disposiciones que son especificaciones del derecho de dirección

\footnotetext{
10 Siguiendo la postura de Plá Rodríguez sostenida respecto de las obligaciones de las partes del contrato de trabajo. Véase Curso de Derecho Laboral. Contratos de trabajo. Tomo II. Vol. I. Montevideo, Uruguay: Acali, 1978, p. 139. Estos derechos del empleador ingresan por aplicación del artículo 1291 inciso segundo del Código Civil uruguayo que indica que los contratos obligan a lo que en ellos se expresa y a todas las consecuencias "según su naturaleza".
} 
Cristina Mangarelli / Derechos del empleador a la organización y dirección de la empresa, y limites

(y del poder disciplinario). Como por ejemplo, la salida y la entrada al establecimiento, el registro de pertenencias del trabajador, el procedimiento en caso de inasistencias al trabajo, etc. Este "derecho" de impartir instrucciones generales es conocido como el "poder reglamentario" del empleador.

En el derecho uruguayo, si bien se admite que el empleador de forma unilateral formule un reglamento interno, dicho reglamento se encuentra sometido al control del juez. El juez podrá entender que alguna disposición del reglamento es ilícita o se encuentra fuera del poder directivo, y por ello resolver en el caso concreto que resulta inaplicable al trabajador.

Últimamente las instrucciones generales no se encuentran sólo en reglamentos o en instructivos internos, sino también en códigos de conducta unilaterales elaborados y aplicados por las empresas.

Resulta interesante observar que los reglamentos, instructivos, y códigos de conducta contienen especificaciones concretas del derecho de dirección formuladas por el empleador a través de reglas generales y abstractas, de aplicación a todos los trabajadores de la empresa. Estas reglas, en tanto constituyen especificaciones del poder de dirección pueden ser modificadas en forma unilateral por el empleador ${ }^{11}$.

Pero también podemos encontrar en dichos instrumentos reconocimientos de derechos a los trabajadores por parte del empleador. En ese caso, entiendo que se trata de compromisos unilaterales "vinculantes" 12 . Corresponde entonces distinguir en dichos contenidos aquello que constituye especificación del derecho de dirección, de los reconocimientos de derechos que puedan haberse formulado, éstos pasan a mi modo de ver a regir las condiciones de trabajo ${ }^{13}$.

\subsection{3 Órdenes o instrucciones referidas a la prestación del trabajo y a otros deberes del trabajador}

Las órdenes o instrucciones estarán referidas al trabajo, pero también a la conducta del trabajador, y a otros deberes que asume el trabajador por el contrato y que tienen que ver con el orden y organización de la empresa ${ }^{14}$. Por ejemplo, el trabajador está obligado a tratar con respeto a los compañeros de trabajo.

En cuanto al contenido del derecho de dirección, refiere a las órdenes o instrucciones sobre modo, tiempo y lugar de la prestación ${ }^{15}$.

Asimismo del derecho de dirección de la empresa se desprende el derecho de vigilar y controlar el cumplimiento de las órdenes impartidas.

\footnotetext{
11 Conforme Krotoschin, op. cit. (n. 4), p. 197. Para la doctrina francesa, los contenidos en los reglamentos internos o instructivos que constituyen especificaciones del poder de dirección pueden ser modificadas por el empleador. Puede verse Supiot, op cit. (n. 6), p. 274. "El empresario no se halla vinculado jurídicamente por sus decisiones de gestión", pero entiende que otras disposiciones que crean derechos, son vinculantes, op cit. (n. 6), p. 276. PéLissier; Supiot; JeAmmaud analizan los diferentes tipos de disposiciones en los reglamentos y mencionan la jurisprudencia que sostiene que aquellas que no constituyen materia del poder de dirección y son favorables al trabajador, son compromisos vinculantes, op. cit. (n. 7), p. 996.

12 Conforme postura de la doctrina francesa, ver Supiot, op. cit. (n. 6), p. 272. También Pélissier; Supiot; Jeammaud, op. cit. (n. 7), p. 996

13 Postura que he sostenido en Códigos de conducta en el marco de la responsabilidad social de la empresa. Montevideo, Uruguay: Fondo de Cultura Universitaria, 2009, pp. 76-81.

14 Ver en este sentido Hueck y Nipperdey, op. cit. (n. 2), p. 99.

15 Ver Alonso Olea y Emilia Casas Baamonde, op. cit. (n. 1), p. 316.
} 
También se reconoce al empleador el derecho de controlar el uso de los bienes propiedad de la empresa asignados al trabajador, y de realizar otros controles relativos a la seguridad de las instalaciones y bienes.

\subsection{4 Órdenes o instrucciones sobre el cumplimiento de la prestación y otros deberes}

a) Órdenes o instrucciones sobre el modo, tiempo y el lugar: el alcance del derecho de dirección refiere al modo, tiempo y lugar de la prestación, teniendo en cuenta el "trabajo contratado y la categoría profesional".

Como el contrato de trabajo es de ejecución continuada, las "concreciones" en el modo de la prestación se realizarán a medida de que se ejecuta el contrato ${ }^{16}$.

Se reconoce al empleador el derecho de variar (jus variandi) aspectos relativos al modo, tiempo y lugar de la prestación, pero con límites precisos.

b) Órdenes o instrucciones acerca de la conducta en la empresa y de otros deberes: por el contrato de trabajo el trabajador se obliga a cumplir además de la prestación de tareas otros deberes, como el de respetar la dignidad del empleador, de supervisores y compañeros. Debe observar una conducta acorde con la moral y buenas costumbres en el desempeño del trabajo. Se trata de deberes acerca de la conducta en el ambiente de trabajo.

En algún caso, el deber de conducta puede exigirse fuera del ámbito del trabajo ${ }^{17}$.

El trabajador también debe cumplir las instrucciones impartidas por el empleador acerca de la organización y el orden interno en la empresa (entradas y salidas del establecimiento, registros, etc.).

c) Órdenes o instrucciones relativas a la seguridad e higiene del trabajo: las instrucciones podrán comprender las relativas a la seguridad e higiene del trabajo. El trabajador se encuentra obligado a cumplir las medidas de seguridad por su seguridad individual y la de sus compañeros de trabajo.

d) Órdenes o instrucciones sobre uso de bienes propiedad de la empresa: las instrucciones sobre el uso de los bienes propiedad de la empresa comprenden las máquinas, herramientas de trabajo e instalaciones en general.

\subsubsection{Vigilancia y control del cumplimiento de la prestación y de otros deberes}

El derecho de vigilar y controlar el cumplimiento de las órdenes y de otros deberes se desprende del derecho de dirección del empleador. especial.

Sin embargo, los controles tienen límites, establecidos en muchos casos en la legislación

\subsubsection{Vigilancia y control del uso de los bienes propiedad de la empresa y otros controles}

El empleador tiene derecho a controlar el uso de los bienes de su propiedad que son utilizados por el trabajador en el desempeño de la labor. El trabajador tiene el deber de utilizar dichos bienes para los fines del trabajo para el que se le contrató.

16 Hueck y Nipperdey op. cit. (n. 2), p. 98; Alonso Olea y Emilia Casas Baamonde, op. cit. (n. 1), p. 317.

17 Ver Alonso Olea y Emilia Casas Baamonde, op. cit. (n. 1), p. 317. 


\subsection{JUS VARIANDI}

Como una derivación del derecho de dirección del empleador (y de organización de la empresa), y teniendo en cuenta que el contrato de trabajo es de tracto sucesivo, este contrato confiere al empleador el derecho de variar aspectos no sustanciales referidos a la prestación (modo, tiempo y lugar).

Si bien el reconocimiento de este derecho a una de las partes del contrato de trabajo implica el alejamiento del principio general en materia contractual que establece que el contrato constituye ley para las partes ${ }^{18}$, se admite en consideración de que el contrato se prolonga en el tiempo favoreciendo la continuidad de la relación.

En algunos sistemas este derecho del empleador se encuentra establecido en la ley, en otros como el caso uruguayo, si bien la ley no lo prevé la doctrina y la jurisprudencia lo admiten, aunque con límites.

\subsection{PODER Disciplinario}

El poder disciplinario que el contrato de trabajo asigna al empleador puede ser visto como una consecuencia del derecho de dirección. Si el empleador tiene el derecho de impartir órdenes en la realización del trabajo y de controlar el cumplimiento de las mismas, puede entenderse que también se le haya reconocido el derecho de aplicar sanciones en caso de incumplimiento de las órdenes.

Aun cuando se acepte esta postura, no es indiferente la consideración de que el contrato no se agota en una sola prestación, impidiéndose con el reconocimiento de la potestad disciplinaria al empleador la rescisión del contrato ante cualquier incumplimiento del trabajador.

Como en el caso anterior, esta facultad del empleador de aplicar sanciones tiene límites como veremos.

\section{LÍMITES EN EL EJERCICIO DE LOS DERECHOS DE ORGANIZACIÓN Y DIRECCIÓN DE LA EMPRESA}

\subsection{Derechos del trabajador. Derechos de la persona}

Los límites en el ejercicio de los derechos del empleador de organización y dirección se encuentran precisados por el contenido del contrato individual (las órdenes referirán al tipo de trabajo contratado teniendo en cuenta la categoría profesional), y por los derechos del trabajador protegidos en la Constitución, leyes especiales, convenios colectivos.

Dichos límites también se desprenden del contrato de trabajo. Si bien el contrato de trabajo reconoce derechos al empleador, le fija límites atendiendo a los derechos del trabajador.

Los jueces considerarán en el caso concreto si el empleador ejerció los derechos de organización, dirección y control con exceso. Si existió exceso de su parte, se estará ante una situación de ilicitud o incumplimiento contractual (abuso de derecho). Para determinar si existió ilicitud el juez tendrá en cuenta la posible colisión con los derechos del trabajador.

Como se señaló, el contrato de trabajo atribuye al empleador el derecho de dirección, pero con límites.

\footnotetext{
18 El texto del artículo 1291 inciso primero del Código Civil uruguayo dispone: "Los contratos legalmente celebrados forman una regla a la cual deben someterse las partes como a la ley misma”.
} 
En los países en los cuales el derecho del empleador de dirección se encuentra previsto en la normativa, ésta se encarga de fijar algunos límites indicando, por ejemplo, que debe ejercerse con determinada finalidad (objetiva referida a la empresa), debe tratarse del ejercicio "regular" del derecho, debe evitar el daño, el abuso ${ }^{19}$.

En la actualidad, la consideración de los derechos de "la persona" del trabajador ha llevado a un nuevo enfoque del tema de los derechos del empleador a la organización y dirección de la empresa.

Las protecciones de los derechos de la persona del trabajador surgen de los Pactos Internacionales de Derechos Humanos, de las Constituciones, de las leyes especiales, de los convenios colectivos y del contrato de trabajo.

Muchos países cuentan con acciones de tutela de derechos fundamentales en la Constitución o en la ley. Por ejemplo, en el caso de Chile rige un procedimiento especial de tutela de derechos fundamentales de los trabajadores.

\subsection{CRITERIOS GENERALES PARA PRECISAR LOS LÍMITES}

Algunos criterios generales a tener en cuenta por el juez para precisar los límites del derecho del empleador cuando imparte "instrucciones" y realiza "controles" son los siguientes: buena fe; justificación de la medida; razonabilidad; proporcionalidad; no discriminación.

\section{a) Buena fe}

Los contratos deben ejecutarse de buena fe. Ello implica que los derechos que el contrato atribuye al empleador deban ejercerse de buena fe. El principio de la buena fe opera como límite en el ejercicio de los derechos del empleador.

La vulneración de este deber de obrar de buena fe llevará a que el Juez determine en el caso concreto la existencia de "abuso de derecho"20.

\section{b) Justificación. Razonabilidad}

No se requiere que el empleador justifique las instrucciones que imparte. De todos modos, no puede ejercer el derecho de dirección con una finalidad desviada o con motivo ilícito. La necesidad de que exista justificación aparece en la utilización y aplicación de algunos controles y sistemas de vigilancia adoptados por el empleador.

El criterio de razonabilidad resulta aplicable para observar el ejercicio de cualquier derecho, y en este caso se tomará en cuenta para analizar la implementación de los controles impuestos por el empleador.

\section{c) Proporcionalidad}

Debe tenerse en cuenta la justificación de la medida de control y considerar si su aplicación respeta la debida proporcionalidad, teniendo en cuenta las particularidades del caso concreto, la finalidad que se persigue y los derechos de las partes que están en juego.

\footnotetext{
19 Ver por ejemplo, la Ley de Contrato de Trabajo argentina artículo 65, y el Estatuto de los trabajadores español artículo 20 numerales 2 y 3 .

20 Ver Gamarra, Jorge. Tratado de derecho civil uruguayo. Tomo XIX. Montevideo, Uruguay, 1981, pp. 200, 206-207. Analicé la cuestión de la buena fe como límite en el ejercicio de los derechos del empleador en "La buena fe en el derecho del trabajo", en: Revista Derecho Laboral no 234, abril- junio 2009, Montevideo, Uruguay, pp. 330-331.
} 
d) No discriminación

Las medidas de control no pueden ser discriminatorias. Deben utilizarse sistemas objetivos de selección para la realización de los controles.

\subsection{LÍMITES EN LAS ÓRDENES}

\section{a) Tareas de la categoría laboral}

Las tareas correspondientes a la categoría laboral pueden estar descritas en las leyes, en los convenios colectivos, en el propio contrato de trabajo ${ }^{21}$.

No todas las tareas que conlleva la categoría podrán encontrarse detalladas en el contrato o en la normativa. Puede ocurrir que se trate de tareas que si bien no realizaba el trabajador correspondan a la categoría para la que fue contratado, estén o no descritas en la norma ${ }^{22}$. Las tareas serán las corrientes o del uso en la profesión. Pueden plantearse dificultades en la consideración de las "tareas accesorias" a las de la categoría.

En casos excepcionales podrá exigirse la realización de tareas distintas a las de la categoría para la que fue contratado el trabajador, teniendo en cuenta la obligación de colaboración ${ }^{23}$.

\section{b) Trabajo ilícito}

El trabajador debe cumplir las órdenes, y en su caso reclamar o ejercer alguna acción ${ }^{24}$ si entiende que no corresponden, por ejemplo, por tratarse de tareas distintas a las de la categoría en la cual se lo contrató.

Pero el trabajador no se encuentra obligado a obedecer las órdenes que constituyen un delito, o un ilícito, o son contrarias a la moral o buenas costumbres. Este límite surge del propio contrato de trabajo ${ }^{25}$, por lo que no requiere norma expresa que así lo establezca.

c) Trabajo que pone en peligro la integridad física del trabajador o de un compañero

El derecho a negarse a cumplir una orden que ponga en peligro su seguridad o salud o la de un compañero de trabajo surge de la naturaleza del contrato de trabajo, y rige aun cuando no esté especialmente previsto en la legislación del país.

El Convenio Internacional del Trabajo $\mathrm{N}^{0} 167^{26}$ sobre seguridad y salud en la construcción, establece el derecho del trabajador de alejarse de una situación de peligro cuando entraña un riesgo inminente y grave para su seguridad y salud, y la obligación de informar sin demora a su superior (artículo 12 numeral 1).

\footnotetext{
21 En el caso uruguayo, la descripción de las categorías por lo general se encuentra en los convenios colectivos, muchos de los cuales se han celebrado en el ámbito de los Consejos de Salarios.

22 La jurisprudencia uruguaya ha señalado -en algunos casos- que si bien el trabajador no realizaba las tareas que luego le exigió el empleador, se encontraban incluidas en las de la categoría para la que había sido contratado.

23 Y por un corto período. En cuanto a si puede requerirse la realización de horas extras atendiendo a una especial situación de la empresa y teniendo en cuenta la obligación de colaboración, entiendo que aún en dicha situación el trabajador podrá negarse con motivo justificado.

24 Un derecho a "resistir la orden" si considera el trabajador que con ella se modifican las condiciones del contrato no se ha aplicado en la práctica en el derecho uruguayo.

25 Así lo admite la doctrina tradicional. Ver por ejemplo, Plá Rodríguez, op. cit. (n. 10), p. 147.

26 Ratificado por Uruguay por ley No 17.584 de 14.11.2002.
} 
d) Derechos de la persona del trabajador y deber de protección al trabajador

En el ejercicio del derecho de dirección el empleador debe respetar los derechos de la persona del trabajador. En especial debe respetar y proteger la "dignidad del trabajador". En ello queda comprendido el modo que se utiliza para impartir las órdenes, el tono de voz, las expresiones, el trato en general al trabajador. No se admiten burlas, ni comentarios despreciativos, ni violencia alguna en el ejercicio del derecho de dirección ${ }^{27}$.

Asimismo el empleador en el ejercicio del derecho de dirección de la empresa no puede violentar "otros derechos fundamentales del trabajador, como intimidad, vida privada, honra", entre otros.

También se encuentra impedido en la aplicación del referido derecho de dirección "de causar daño a la persona del trabajador, o a sus bienes".

Resulta de interés señalar que Alonso Olea y Casas Baamonde en el inicio del estudio que realizan del poder de dirección, hacen referencia al "deber de protección al trabajador" a cargo del empleador. Este deber de protección se desprende de la circunstancia de que el trabajo se presta con sujeción a órdenes ${ }^{28}$.

Se trata del deber de proteger al trabajador respecto de todo daño en la ejecución de la labor. Ello ya está señalando un límite preciso en el ejercicio del derecho de dirección del trabajo: "debe evitar causar daño al trabajador". El deber de indemnidad del empleador no está referido sólo a la cuestión de la "seguridad e higiene", sino también a la "dignidad".

El derecho del empleador a la dirección de la empresa y sus límites ante la vulneración de "derechos fundamentales del trabajador" (dignidad, intimidad, vida privada, integridad física y psíquica entre otros) aparece en las sentencias de varios países. Por ejemplo, el Tribunal Superior de Trabajo de Brasil en sentencia de 27 de octubre de 2010 mantuvo la condena a una empresa a pagar una indemnización por el daño moral padecido por una trabajadora quemada con una plancha caliente por el gerente al no acatar la orden de levantarse de una silla. Se indicó que la empresa es responsable por el acto del gerente que aconteció de modo de obligar a la trabajadora a cumplir la orden funcional ${ }^{29}$.

Si bien al empleador le asiste el derecho a realizar investigaciones ante posibles irregularidades en la empresa como consecuencia de su derecho de vigilancia y control, la investigación no puede realizarse de modo de vulnerar derechos fundamentales de los trabajadores ${ }^{30}$.

\footnotetext{
27 En algunos códigos de conducta las empresas indican que no trabajarán con proveedores que utilicen como "sanción disciplinaria" la violencia física o la psicológica.

28 Señala Barbagelata que el empleador no sólo no puede cometer actos ilícitos o contrarios a la moral o a las buenas costumbres, sino que debe abstenerse de realizar actos que perjudiquen el prestigio del trabajador o su reputación profesional. Véase Derecho del Trabajo. Tomo I. Vol. 2. $3^{\circ}$ ed. Montevideo, Uruguay: Fondo de Cultura Universitaria, 2007, p. 190. Ibid., p. 315. En el mismo sentido Кrotoschin (con relación al deber del empleador de previsión), op. cit. (n. 4), pp. 196-197.

29 (TST-RR-69200-19.2005.5.01.0050). Las sentencias del Tribunal Superior de Trabajo de Brasil mencionadas en este trabajo me las proporcionó Manuel Carlos Toledo Filho a quien agradezco. Pueden verse en www.tst.jus.br

30 El Tribunal Superior de Trabajo de Brasil en sentencia de 23 de setiembre de 2009 confirmó la condena a una empresa a pagar a una trabajadora (a quien se le imputaban actos de sabotaje respecto de una máquina) una suma de dinero por dańo moral, por haberla mantenido bajo vigilancia armada varias horas para ser interrogada, sufriendo presión psicológica e insultos. Se entendió que se había configurado "abuso del poder directivo" (TST-RR-371/2007-040-15-00.3).
} 


\subsection{LÍMITES EN LOS CONTROLES ${ }^{31}$}

El empleador tiene derecho a controlar el cumplimiento de la tarea y de otros deberes del trabajador que se desprenden del contrato de trabajo, y a efectuar controles relativos a la seguridad de los bienes e instalaciones de la empresa.

En la realización de dichos controles, tiene límites (justificación de la medida de control, razonabilidad y proporcionalidad de la misma, no discriminación, buena fe).

\section{a) Registros}

Los controles y registros se admiten por la doctrina y la legislación de algunos países, pero con límites precisos. En algunos casos, dichos límites se encuentran en la legislación. Por ejemplo, en el Código de Trabajo de la República Dominicana (artículo 43), y en la Ley de Contrato de Trabajo argentina (artículo 70).

Los controles deben realizarse respetando la dignidad del trabajador, con sistemas de sorteo u otros que impidan la discriminación.

En varios países de América del Sur se encuentran sentencias relativas a revistas abusivas. Por lo general, en estos casos se condena al empleador a pagar una indemnización por el daño moral padecido ${ }^{32}$, sin perjuicio de admitir el despido indirecto.

\section{b) Cámaras de vigilancia}

Las cámaras de vigilancia son utilizadas cada vez con mayor frecuencia por el empleador para controlar la seguridad de los bienes e instalaciones. Sin embargo, también se emplean para controlar el cumplimiento de la tarea por el trabajador. Se aprecian distintas posturas en la jurisprudencia de los países de América Latina en torno a la utilización de estas cámaras como sistema de control.

En mi opinión, pueden ser utilizadas en la medida de que se requiera su uso por razones de seguridad o de necesidad por el tipo de tarea de que se trate. Y ser instaladas de modo de causar el menor daño al trabajador, teniendo en cuenta sus derechos fundamentales (vida privada). No podrían ser empleadas con la finalidad exclusiva de vigilancia del trabajador (del cumplimiento de la tarea).

\section{c) Pruebas de alcohol y drogas}

En algunos sistemas las pruebas de alcohol a solicitud del empleador son admitidas. Incluso se encuentran previstas en la normativa y en los convenios colectivos. También se ha comenzado por parte de algunas empresas a requerir al trabajador al inicio de la relación su consentimiento para realizarle pruebas de alcohol e incluso de drogas ${ }^{33}$.

Los límites pueden estar en los derechos a la intimidad y vida privada del trabajador. Sin embargo, estos derechos del trabajador pueden ceder o admitir cierta limitación ante la necesidad del empleador de efectuar este tipo de pruebas, teniendo en cuenta la especialidad de la actividad de que se trate.

\footnotetext{
31 El análisis de los controles del empleador y el derecho a la vida privada del trabajador puede verse en Mangarelli, Cristina. "Protección de la vida privada del trabajador en el lugar de trabajo". Informe General Tema III. VIII Congreso Regional Americano, Cartagena de Indias 25-28 mayo 2010. Publicado en: Revista Derecho Laboral no 238, abril-junio 2010, Montevideo, Uruguay, pp. 325-380.

32 En Uruguay, el Tribunal de lo Contencioso Administrativo en sentencia No 660 de 28.8.2000 confirmó la multa impuesta a una empresa de seguridad por realizar un registro personal violatorio de los derechos de la personalidad protegidos en la Constitución.

33 En Uruguay, el Tribunal de Apelaciones del Trabajo de 3er turno en sentencia No 381 de 17 de agosto de 2004 admitió el despido sin indemnización de una trabajadora de un hotel a quien se le practicó una prueba en la orina al azar y se le encontró residuos de droga. El Tribunal tuvo en cuenta que el reglamento de la empresa establecía la prohibición de concurrir al trabajo bajo influencia de drogas ilegales.
} 


\section{d) Uso del correo electrónico}

Con relación al correo electrónico proporcionado por el empleador se han planteado distintas posturas. Se consideran en estos casos el derecho del empleador de controlar el uso de una herramienta de su propiedad (que ha asignado al trabajador para el cumplimiento del trabajo), y el derecho del trabajador a la inviolabilidad de la correspondencia privada protegido en las Constituciones.

Por lo general se admite en los países de América del Sur el despido sin indemnización cuando está acreditado que el trabajador utilizó el correo electrónico para fines personales, o contrarios a la empresa, o para enviar pornografía.

No aparece claramente precisado en la jurisprudencia de algunos países de América del Sur si el empleador puede entrar en el correo electrónico asignado al trabajador sin autorización judicial, para obtener de allí la prueba que acredite la mala conducta para presentar en el juicio.

En algunas sentencias, los Tribunales toman en cuenta el derecho a la vida privada del trabajador y a la inviolabilidad de la correspondencia, pero en otras se indica que el amparo constitucional de dichos derechos no se aplica al caso dado que se trata de una herramienta de propiedad del empleador. En algunos países, cuando el empleador ha comunicado previamente que el correo electrónico debe ser utilizado para el cumplimiento del trabajo y que será controlado, las sentencias indican que en ese caso no hay expectativa del trabajador de privacidad.

\section{e) Solicitud de datos personales}

Si bien no se admite que el empleador requiera al trabajador -al inicio o durante la relación de trabajo- que le proporcione datos personales, puede exigirlos si dichos datos inciden en el trabajo o lo afectan. En el caso de las empresas de tendencias, se admite el derecho del empleador de conocer algunos datos del trabajador, que si bien son personales tienen que ver con el tipo de empresa de que se trata ${ }^{34}$.

La protección de datos personales de los trabajadores en la actualidad se ha visto reforzada con las leyes de protección de datos personales aprobadas en varios países, que también se aplican a la relación de trabajo.

\subsection{LÍMITES EN EL EJERCICIO DEL JUS VARIANDI}

El derecho del empleador de variar ciertos aspectos de la relación (modo, tiempo y lugar) tiene límites. En algunos casos los límites están precisados en la normativa, en otros como ocurre en el caso uruguayo dichos límites han sido establecidos por la doctrina y la jurisprudencia.

Como todo derecho no puede ser ejercido en forma desviada, contraria a la finalidad para la cual fue establecido, o por "motivo ilícito". Por ejemplo, no puede utilizarse como represalia por el ejercicio de derechos por parte del trabajador.

Pero también se ha establecido como límite, el derecho del trabajador a que no se le cause "daño". La configuración del daño que da lugar por ejemplo, al despido indirecto, queda a criterio del juez. Por lo general se entiende que el daño debe ser de entidad.

\footnotetext{
34 También puede resultar admisible en las empresas de tendencias que se exija al trabajador determinado comportamiento en la vida privada. Ver Alonso Olea y Emilia Casas BaAmonde, op. cit. (n. 1), pp. 317-318.
} 
Cristina Mangarelli / Derechos del empleador a la organización y dirección de la empresa, y límites

\subsection{LÍMITES EN EL EJERCICIO DEL PODER DISCIPLINARIO}

Varios criterios se utilizan por la jurisprudencia en distintos países para limitar el poder disciplinario del empleador. No puede utilizarse con una finalidad desviada o de represalia; rigen los principios de proporcionalidad, razonabilidad e inmediatez; no pueden aplicarse dos sanciones por el mismo hecho; no puede ejercerse con violencia.

El principio de la buena fe viene siendo utilizado para precisar los límites en el poder disciplinario del empleador. La Suprema Corte de Justicia de Uruguay en sentencia No 418/2003 -relativa a una empresa que realizó un sumario cuyo resultado arrojó que el trabajador no tenía responsabilidad alguna en los hechos que se le imputaban, pese a lo cual despidió al trabajador (aunque le pagó la indemnización por despido) - entendió que existió violación del deber de obrar de buena fe porque una vez dispuesto el sumario el trabajador "tenía derecho" a que se respetara el resultado del mismo, y condenó a la empresa a abonar una suma por daño moral ${ }^{35}$.

\subsection{Acoso laboral. Moral. Sexual}

En el momento actual el tema del derecho de dirección del empleador también debe ser analizado teniendo en cuenta la cuestión del acoso y de otras formas de violencia en el trabajo. La situación de acoso o violencia puede darse en ocasión del ejercicio del poder de dirección y disciplinario.

Las leyes en muchos países establecen el deber del empleador de prevención del acoso laboral y de adoptar medidas (realizar determinadas acciones ante denuncias de los trabajadores o del sindicato), lo que apareja limitaciones de los derechos de organización y de dirección.

Las situaciones de "acoso moral" no pueden reducirse a aquellas en las que las empresas adoptan determinados comportamientos con la finalidad de que el trabajador se canse y se retire del trabajo. En ocasiones los comportamientos abusivos del empleador tienden a que el trabajador "se adapte" a la pautas del trabajo impuestas por la empresa o aumente la producción ${ }^{36}$.

\subsection{LA VOZ DE LOS TRABAJADORES EN LA EMPRESA ¿LÍMITE AL DERECHO DE DIRECCIÓN?}

La "voz de los trabajadores" en la empresa entendida como un derecho de expresión de los trabajadores con independencia de que se trate de "representantes sindicales" o de "representantes electos", viene siendo estudiada e incluso regulada en algunos sistemas ${ }^{37}$.

En los países en los que no se cuenta con una normativa especial en tal sentido, algunas disposiciones provenientes de leyes, decretos, convenios colectivos y Convenios Internacionales de Trabajo e incluso códigos de conducta unilaterales, dan cuenta de derechos de los trabajadores "a estar informados" y "a expresar opinión” con relación a ciertos temas.

\footnotetext{
35 La Corte consideró que el despido fue "abusivo".

36 Es el caso de la sentencia del Tribunal Superior de Trabajo de Brasil de 29 de noviembre de 2006 referida a una empresa de bebidas en la que se realizaban reuniones para "motivar" a los trabajadores, en las que recibían castigos si no habían llegado a las metas impuestas por la empresa. Se condenó a la empresa a pagar una suma de dinero al trabajador por el dańo moral causado por actos abusivos (TST-AIRR-1370/2005-006-20-40.0).

37 El derecho francés prevé una normativa especial al respecto que ha dado lugar a elaboraciones de la doctrina de particular interés. Ver Pélissier; Supiot y Jeammaud, op. cit. (n. 7), pp. 1029-1034. El análisis general del tema y la consideración de estos derechos del trabajador teniendo en cuenta los Convenios Internacionales de Trabajo sobre seguridad y salud puede verse en JeAmmaud. Antoine. "Représentation des travailleurs et dialogue social au lieu de travail". Informe General Tema 2 en el XIX Congreso Mundial de Derecho del Trabajo y de la Seguridad Social, Sydney, Australia 1-4 septiembre 2009, pp. 3-19.
} 
Si los trabajadores tienen derecho a ser "informados" a través de sus representantes, por ejemplo, acerca de las medidas de seguridad y salud implementadas por el empleador (Convenio Internacional de Trabajo № 155 sobre seguridad y salud, artículo 19 lit. c), e incluso si "los trabajadores" tienen derecho a "examinar" los aspectos de la seguridad y salud relacionados con su trabajo y a "expresar su opinión" al respecto (derecho a ser consultados por el empleador) como lo establece el CIT No 155 artículo 19 lit. e), entonces hay cierta limitación del derecho de dirección del empleador ${ }^{38}$.

\subsection{DERECHO DEL EMPLEADOR DE DIRECCIÓN Y LIBERTAD SINDICAL}

La protección de la libertad sindical en los distintos sistemas impone al empleador deberes que limitan su facultad de dirección.

Por ejemplo, en el caso uruguayo la ley No 17.940 de 2 de enero de 2006 no sólo admite el reintegro o reposición del trabajador en caso de despido o de actos que lo perjudiquen por razones sindicales, sino que establece la retención de la cuota sindical, el derecho a la cartelera sindical y a la licencia sindical. Todo ello implica limitaciones al derecho de organización y dirección del empleador, que cede ante la protección y promoción de la libertad sindical.

\section{ILICITUD EN EL EJERCICIO DEL DERECHO DE DIRECCIÓN (ABUSO DE DERECHO)}

\subsection{Principios generales}

Si un derecho se ejerce con exceso y causa un daño nos encontramos en el campo de la ilicitud. Tratándose de un derecho del empleador, lo que aquí se va a analizar es la situación de abuso en el ejercicio de este derecho por parte del empleador, que acarrea la violación de derechos del trabajador y ocasiona daño.

Si hay abuso de derecho y se causa un daño, se genera la obligación de reparar dicho daño de acuerdo a la teoría del abuso de derecho del derecho civil. Para que ello tenga lugar deben estar presentes los elementos de la responsabilidad civil (hecho ilícito, culpa, nexo causal y daño).

En la actualidad, la jurisprudencia en muchos países de América del Sur admite la reparación del daño proveniente del "abuso del poder directivo del empleador". ¿Cuándo se configura abuso del derecho de dirección? Cuando este derecho se ejerce con un fin desviado o distinto para el que fue previsto, con motivo ilícito o con intención de dañar.

\subsection{RESPONSABILIDAD DEL EMPLEADOR}

Ante el abuso del derecho de dirección del empleador, el trabajador podrá:

a) considerarse indirectamente despedido y reclamar la indemnización tarifada por despido y según el caso, la reparación del daño moral;

\footnotetext{
38 Ratificado por Uruguay por ley No 15.965 de 28 de junio de 1988, reglamentado por el decreto No 291/2007 de 13.8.2007. El artículo 19 del CIT No 155 prevé que deben adoptarse disposiciones a nivel de empresa para que "los trabajadores o sus representantes" estén habilitados para "examinar" los aspectos de seguridad y salud, y "sean consultados" por el empleador (lit. e); "el trabajador informará" a su superior cualquier situación de peligro inminente o grave para su vida o salud, y no podrá exigirse a los trabajadores que reanuden el trabajo si existe un peligro grave o inminente para su vida o salud (lit. f).
} 
b) intimar al empleador (si así lo admite el ordenamiento del país) el cumplimiento del contrato que le impone el deber de respetar al trabajador y de asegurar el respeto en el lugar de trabajo, y en su caso además solicitar daños y perjuicios,

c) seguir trabajando y reclamar la reparación del daño que se le ha causado (generalmente daño moral).

En algunos sistemas también se prevé una "acción de tutela de derechos fundamentales del trabajador". Si existe abuso del derecho de dirección del empleador que violente un derecho fundamental del trabajador, la acción de tutela de derechos fundamentales permite obtener no sólo la reparación del daño, sino también una resolución judicial que ordene al empleador el cese del comportamiento abusivo y otras medidas (reintegro, obligación de tomar alguna medida específica, obligación de formar a los trabajadores acerca de determinada temática).

Ello se observa en el caso de la acción de tutela de derechos fundamentales en Chile, por ejemplo en la sentencia del Primer Juzgado de Letras del Trabajo de Santiago de 26 de abril de 2010 referida a la protección de la libertad religiosa. La trabajadora recibió un trato inadecuado desde que empezó a profesar la religión musulmana (burlas, insultos, comentarios humillantes sobre su religión) que le ocasionó padecimiento que alteró su salud psíquica, y sufrimiento. En esta sentencia se entendió que la demandada vulneró el derecho a la no discriminación por religión, y se le ordenó "cesar tal vulneración poniendo fin a los malos tratos verbales y diferencias...entre la trabajadora... respecto del resto de los operadores telefónicos” bajo sanción de multa, trasladar a los jefes, realizar una capacitación (no inferior a seis horas) para la totalidad de los trabajadores relativa al trato respetuoso, sin perjuicio de la indemnización del daño moral.

\section{DERECHO DEL EMPLEADOR DE DIRECCIÓN Y HUELGA}

El tema del derecho de dirección y huelga es analizado por algunos autores en especial en la doctrina francesa ${ }^{39}$. La cuestión puede ser diferente según el país de que se trate teniendo en cuenta las particularidades del derecho positivo.

La posible colisión de derechos puede plantearse en especial ante la huelga atípica. En el caso uruguayo, aparece en la modalidad de la ocupación de los lugares de trabajo. Luego de vacilaciones jurisprudenciales que rechazaban el pedido de desocupación de los lugares de trabajo, la jurisprudencia comenzó a admitir la desocupación solicitada por los trabajadores no ocupantes y por el empleador, atendiendo al equilibrio de los derechos.

En estas sentencias se fundamenta la desocupación de los lugares de trabajo por la lesión al derecho al trabajo de los trabajadores no ocupantes, y también por la vulneración de las libertades de industria y de comercio protegidas en la Constitución ${ }^{40}$.

\section{CONCLUSIÓN}

El tema del derecho de dirección del empleador tiene en la actualidad un nuevo enfoque, en especial por los límites de este derecho en función de los derechos fundamentales de la persona

\footnotetext{
39 Ver Pélissier; Supiot; Jeammaud; op. cit. (n. 7), pp. 1276-1285.

40 Por ejemplo, Juzgado Letrado de Primera Instancia en lo Civil de $5^{\circ}$ turno sentencia No 59 de 21 de setiembre de 2006, que fue confirmada.
} 
del trabajador que encuentran amparo en la normativa laboral, y en las Constituciones y Pactos Internacionales de Derechos Humanos. Estas tutelas han venido a reforzar las protecciones especiales del derecho del trabajo.

Por ello el abuso del poder directivo no se sanciona sólo con el despido indirecto o con la reparación del daño moral, sino también con otros mecanismos que prevén las acciones de tutela de derechos fundamentales, que habilitan a ordenar al empleador el cese de la vulneración del derecho y la implementación de medidas que refieren al ámbito de dirección y organización de la empresa.

\section{BILIOGRAFÍA}

Barbagelata, Héctor-Hugo. Derecho del Trabajo. Tomo I. Vol. 2. 3o ed. Montevideo, Uruguay: Fondo de Cultura Universitaria, 2007.

Gamarra, Jorge. Tratado de derecho civil uruguayo. Tomo XIX. Montevideo, Uruguay, 1981.

Hueck, Alfred; Nipperdey, H. C. Compendio de derecho del Trabajo. Madrid, Espańa: Editorial Revista de Derecho Privado, 1963.

Jeammaud, Antoine. "Représentation des travailleurs et dialogue social au lieu de travail”. Informe General Tema 2 en el XIX Congreso Mundial de Derecho del Trabajo y de la Seguridad Social, Sydney, Australia 1-4 septiembre 2009.

Krotoschin, Ernesto. Tratado práctico de derecho del trabajo. Vol. I. $3^{a}$ ed. Buenos Aires, Argentina: Ediciones Depalma, 1978.

Mangarelli, Cristina. "La buena fe en el derecho del trabajo", en: Revista Derecho Laboral no 234, abril- junio 2009, Montevideo, Uruguay, pp. 330-331.

Mangarelli, Cristina. Códigos de conducta en el marco de la responsabilidad social de la empresa. Montevideo, Uruguay: Fondo de Cultura Universitaria, 2009.

Olea, Alonso; Casas Baamonde, Emilia. Derecho del Trabajo. 10 ed. Madrid, España: Universidad Complutense de Madrid, 1988.

Palomeque López, Manuel Carlos; Álvarez de la Rosa, Manuel. Derecho del Trabajo. 17o ed. Madrid, España: Editorial Universitaria Ramón Areces, 2009.

Pélissier, Jean; Supiot, Alain; Jeammaud, Antoine. Droit du travail. 23e Edition. París, Francia: Dalloz, 2006.

Plá Rodríguez, Américo. Curso de Derecho Laboral. Contratos de trabajo. Tomo II. Vol. I. Montevideo, Uruguay: Acali, 1978.

Supiot, Alain. Crítica del derecho del trabajo. Madrid, Espańa: Ministerio de Trabajo y Asuntos Sociales, 1994. 